Wilfrid Laurier University

Scholars Commons @ Laurier

Biology Faculty Publications

Biology

2009

\title{
Cuscuta Jepsonii (Convolvulaceae): An Invasive Weed or an Extinct Endemic?
}

Mihai Costea

Wilfrid Laurier University, mcostea@wlu.ca

Saša Stefanović

University of Toronto

Follow this and additional works at: https://scholars.wlu.ca/biol_faculty

Part of the Biology Commons

\section{Recommended Citation}

Costea, Mihai and Stefanović, Saša, "Cuscuta Jepsonii (Convolvulaceae): An Invasive Weed or an Extinct Endemic?" (2009). Biology Faculty Publications. 50.

https://scholars.wlu.ca/biol_faculty/50

This Article is brought to you for free and open access by the Biology at Scholars Commons @ Laurier. It has been accepted for inclusion in Biology Faculty Publications by an authorized administrator of Scholars Commons @ Laurier. For more information, please contact scholarscommons@wlu.ca. 


\title{
Cuscuta Jepsonit (Convolvulaceae): AN INVASIVE WEED OR AN EXTINCT ENDEMIC? ${ }^{1}$
}

\author{
Mihai Costea ${ }^{2,4}$ And SAŠA Stefanović ${ }^{3}$ \\ ${ }^{2}$ Department of Biology, Wilfrid Laurier University, 75 University Avenue W, Waterloo, Ontario N2L 3C5, Canada; and \\ ${ }^{3}$ Department of Biology, University of Toronto, 3359 Mississauga Road, Mississauga, Ontario, L5L 1C6, Canada
}

\begin{abstract}
Despite their ecological significance, parasitic plants face more conservation challenges than do autotrophic plants. This is especially true for the groups that include weedy or invasive species such as Cuscuta. While approximately half of the Cuscuta (dodders) species may require conservation measures, the genus as a whole is sometimes posted on governmental lists of noxious or quarantine weeds. Our study challenges this stereotype and uses the case of $C$. jepsonii (Jepson's dodder) to illustrate the precarious biodiversity and conservation status faced by many dodder species. Until now, Jepson's dodder has been known only from its type collection. Consequently, its phylogenetic affinities, morphological variation, and ecology have remained unknown, and the species is currently ambiguously considered either synonymous to the invasive North American weed C. indecora or to an extinct endemic from California. Using molecular data from newly found collections, we infer that $C$. jepsonii belongs to $C$. californica species complex, instead of $C$. indecora clade. Also, we discuss the conservation of this species within the broader biological and ecological context of Cuscuta in general.
\end{abstract}

Key words: biodiversity; conservation; Convolvulaceae; Cuscuta jepsonii; dodders; ecology; extinct; invasive; parasitic plants; host specificity; phylogeny.

Parasitism has evolved independently at least 12 times in the angiosperms (Nickrent, 2009). Parasitic plants have been described as keystone species and ecosystem engineers because they impact multiple trophic levels and may even alter the abiotic environment (reviewed by Press and Phoenix, 2005). Yet the conservation of parasitic plants is fraught with more challenges than that of autotrophic plants (Marvier and Smith, 1997). Indeed, the slogan "equal rights for parasites" was coined by Windsor (1995) in an attempt to draw the attention of the scientific community to the bias against parasitic animals that pervades contemporary conservation biology. This situation applies particularly well to Cuscuta (dodders, Convolvulaceae), a genus of ca. 180 species of stem parasites with reduced scalelike leaves, and filiform stems that attach to the host through numerous haustoria (Yuncker, 1932; Kuijt, 1969).

Dodders are placed indiscriminately as Cuscuta spp. on Canadian provincial lists such as "noxious weeds" in British Columbia, Manitoba, Ontario, and Québec, and as "restricted weeds" (destroyed when found) in Alberta (Costea and Tardif, 2006; Rice, 2009). In the USA, "native and widely distributed species" are exempted from the federal noxious weed list (USDA, APHIS, 2006), despite the fact that some of these dodders (e.g., C. campestris) are invasive weeds (Parker and Riches, 1993; Holm et al., 1997; Costea and Tardif, 2006). Even so, the

1 Manuscript received 17 December 2008; revision accepted 20 April 2009.

The authors thank M. Wright and M. Welsh for fieldwork on Mount Shasta, D. Burge for generously sharing the unpublished information on Ceanothus, and T. Dickinson, D. Nickrent, S. Ramsay, M. Simmons, and an anonymous reviewer for critical comments on earlier versions of the manuscript. This research was supported by NSERC of Canada Discovery grants to M.C. (327013-06) and S.S. (326439-06).

4 Author for correspondence (e-mail: mcostea@wlu.ca)

doi:10.3732/ajb.0800425 legislatures of Arizona, Arkansas, Massachusetts, Michigan, and Oregon contradict the U. S. federal provision and, similarly to the Canadian provinces, place dodders in bulk on lists such as "Prohibited Noxious Weeds", "Quarantine", or "Class A Noxious Weed" (Rice, 2009; USDA, NRCS, 2009). In the case of Cuscuta, the negative stereotype-parasites are dangerous and must be destroyed-is perpetuated by extrapolating the true danger posed by a limited number of species $(\sim 15$ species considered as weeds worldwide; Parker and Riches, 1993; Dawson et al., 1994) to the scale of an entire genus, regardless of the fact that the vast majority of dodders are not weeds.

Similarly to other parasitic plants (e.g., Rhinanthus, Ameloot et al., 2006; Bardgett et al., 2006), Cuscuta species play an important role in the ecosystems. They have the capacity to reduce hosts' biomass and alter hosts' allocation patterns, as well as to significantly modify the structure of plant communities (Pennings and Callaway, 2002). For example, although it represents less than $5 \%$ of the total vegetation biomass, $C$. salina var. major from western North America plays a key role in maintaining diversity in salt marsh plant communities (Pennings and Callaway, 1996; Callaway and Pennings, 1998).

Despite their clear ecological significance, most studies of Cuscuta have focused on the detrimental species and methods for their eradication (reviewed by Dawson et al., 1994; Costea and Tardif, 2006), while natural history and/or systematic research has been comparatively overlooked. Cuscuta jepsonii Yunck. (Jepson's dodder) illustrates well the ambiguous status of many dodder species, from both taxonomic and biodiversity standpoints. Jepson's dodder, described by Yuncker (1921), has been known until now only from the holotype specimen collected by Willis Linn Jepson in 1892 in California. Because it has not been found again for more than a century, the California Native Plant Society (2009) assesses this species as presumably extinct (state rank: SH; global rank: $\mathrm{GH}$ ) and includes it on List 3 ("plants about which we need more information"). On the 
other hand, $C$. jepsonii has been also widely accepted as a synonym of $C$. indecora Choisy var. indecora (Beliz, 1993; ITIS, 2009; USDA, NRCS, 2009), a common weed in the Americas (Prather et al., 1995; Costea et al., 2006a). Last, NatureServe (2009) ignores $C$. jepsonii. These contradictory treatments raise the question as to whether $C$. jepsonii is an invasive weed or a potentially extinct endemic from California.

During a survey of herbarium material from California, we discovered additional specimens of $C$. jepsonii. These specimens have allowed us to expand our knowledge about the morphological variation, ecology, and geographical distribution of C. jepsonii as well as to estimate its phylogenetic position using molecular data. The main objectives of this article are (1) to place $C$. jepsonii within the broad phylogenetic framework of Cuscuta subgenus Grammica, (2) to analyze evolutionary relationships with its closely related species, and (3) to discuss the conservation of this species in the larger biological and ecological context of Cuscuta in general.

\section{MATERIALS AND METHODS}

Morphology and micromorphology-Five new collections of C. jepsonii (Appendix 1) were discovered during our herbarium survey for the upcoming treatments of Cuscuta in the second edition of the Jepson Manual and Flora of North America. Flowers and fruits were rehydrated to document their morphology using a Nikon SMZ1500 stereomicroscope equipped with a PaxCam Arc digital camera and Pax-it 6.8 software (MIS, Villa Park, Illinois, USA). Micromorphology was studied with a scanning electron microscope (SEM) Hitachi (Tokyo, Japan) S-570 at $10 \mathrm{kV}$; samples were coated with $30 \mathrm{~nm}$ gold using an Emitech K 550 (Soquelec Ltd., Mississauga, Ontario, Canada) sputter coater (Costea et al., 2006a; Costea, 2007 onward). The conservation status was assessed using NatureServe (2009) ranks and criteria.

Phylogenetic analyses-Of five newly discovered collections of C. jepsonii, only one specimen (Munz 16294, RSA; Appendix 1) was deemed to be of sufficient quality and quantity for molecular studies. To infer the phylogenetic affinities of this species within Cuscuta subg. Grammica, we used multiple sequences from two plant genomes. From the plastid genome (ptDNA), we targeted a noncoding region containing the $\operatorname{trn} L$-UAA intron, $3^{\prime}$ trnL-UAA exon, and intergenic spacer between this exon and $t r n F$-GAA (hereafter called $t r n L-F)$ and the $r b c L$ gene. We also obtained sequences from the internal transcribed spacer (ITS) region of nuclear ribosomal DNA (rDNA) as well as a $\sim 950 \mathrm{bp}$ portion at the $5^{\prime}$ end of the large nuclear ribosomal subunit (26S rDNA). DNA extractions, polymerase chain reaction (PCR) reagents and conditions, amplicon purifications, cloning, and sequencing procedures follow Stefanović et al. (2007) and Costea and Stefanović (2009). The sequences generated in this study have been submitted to GenBank (accessions FJ479697FJ479700). Newly obtained sequences were incorporated into previously aligned matrices from all four regions (Stefanović et al., 2007; Costea and Stefanović, 2009; deposited in TreeBASE at http://treebase.org under study number S2126) using the program Se-Al version 2.0a11 (Rambaut, 2002). The gaps were scored automatically using the program SeqState version 1.32 (Müller, 2005), coded as simple indels (Simmons and Ochoterena, 2000), and appended to the sequence matrix as binary characters.

Two sets of phylogenetic analyses were conducted. The preliminary analyses were designed to place $C$. jepsonii in a broader context of Cuscuta subg. Grammica phylogeny and to test its proposed relationships with $C$. indecora in particular. These analyses were carried out on a large 100-species data set, comprising all major clades of Cuscuta subg. Grammica as defined by Stefanović et al. (2007) and using only trnL-F and ITS sequences. Once the placement of $C$. jepsonii was narrowed to clade A, more detailed analyses of its relationships within this group, informally referred to as the $C$. californica complex, were carried out using a 10-species data set (for details see Costea and Stefanović, 2009) and all four sequenced regions.

Parsimony searches were conducted in the program PAUP* version $4.0 \mathrm{~b} 10$ (Swofford, 2002). For the broad-scale analyses, searches for most parsimonious (MP) trees were performed using a two-stage strategy. First, the search involved 1000 replicates with random stepwise addition (RAS) of taxa, tree-bisection- reconnection (TBR) branch swapping saving no more than 10 trees per replicate, and MULTREES option off. In the second stage, all trees in memory were analyzed with the same settings except the MULTREES option on. Given the smaller number of terminal units (46 accessions), the fine-scale parsimony analyses were run in a single step, with 1000 RAS, TBR branch swapping, but with MULTREES set to increase without limit. For both sets of analyses, the internal support for clades was inferred by nonparametric bootstrapping (Felsenstein, 1985) using 200 pseudoreplicates, each with 20 RAS, TBR branch swapping, and MULTREES option off (DeBry and Olmstead, 2000).

Bayesian Markov chain Monte Carlo (MCMC) phylogenetic inferences (Yang and Rannala, 1997) were conducted using the program MrBayes version 3.1.2 (Ronquist and Huelsenbeck, 2003) on the $C$. californica complex data set only. For the details on the model of sequence evolution selection and Bayesian search settings, see Costea and Stefanović (2009). In brief, the analysis consisted of two runs of one million generations each, starting from a random tree, using the default priors and four Markov chains sampled every 100 generations and the TIM $+\mathrm{G}$ model of DNA evolution. Only the nodes receiving $\geq 0.95$ posterior probabilities (PP) were considered to have statistically significant support (Rannala and Yang, 1996). Convergence of the chains was determined by examining the plot of all parameter values and $-\mathrm{lnL}$ scores against generation using the program Tracer version 1.3 (Rambaut and Drummond, 2004). Stationarity was assumed when all parameter values and the $-\operatorname{lnL}$ had stabilized.

\section{RESULTS}

The broad-scale parsimony analysis of Cuscuta subg. Grammica resulted in $>100000$ equally parsimonious trees of 2796 steps each. A schematic consensus tree showing 15 well-supported major clades (labeled $\mathrm{A}-\mathrm{O}$ ) and the backbone relationships among them is presented in Fig. 1A (for detailed trees, see Stefanović et al., 2007). Independent (locus-specific) as well as combined (total-evidence) molecular analyses placed C. jepsonii firmly within clade A, with $100 \%$ BS, in disagreement with its previous tentative placement (based on limited morphological data, see Costea et al., 2006a) in proximity with C. indecora (clade M; Fig. 1A). An additional 74 steps are required to place $C$. jepsonii and $C$. indecora within the same clade. This length penalty does not come as a surprise given that multiple intervening nodes from total-evidence analysis had $100 \%$ BS support (Fig. 1A).

Both Bayesian runs carried out on a data set restricted to the members of the $C$. californica complex (Costea and Stefanović, 2009 ) plus $C$. jepsonii, converged on similar parameter values and $-\operatorname{lnL}$ scores and reached apparent stationarity at no later than 100000 generations. The burn-in of data points, accumulated before asymptotic plateaus were reached, left a total of 18000 combined trees $(2 \times 9000)$ that were summarized as a majority-rule consensus tree (Fig. 1B). The parsimony analysis using the same sequence matrix, but with the addition of gaps coded as binary characters, produced 2142 MP trees, each 994 steps in length $(\mathrm{CI}=0.76 ; \mathrm{RI}=0.94)$. A strict consensus of all equally parsimonious trees (not shown) resulted in relationships topologically identical to those obtained using the Bayesian criterion (Fig. 1B).

According to our results, $C$. jepsonii is nested within the C. californica complex, a group that includes, for the most part, the species circumscribed by Yuncker (1932) in subsections Californicae and Salinae. In agreement with Yuncker's (1921, 1932) original suggestions, Jepson's dodder forms a well-supported (90\% BS; $\geq 0.95 \mathrm{PP}$ ) sister lineage to the subclade that includes $C$. californica, $C$. brachycalyx, and $C$. occidentalis (Fig. 1B). Furthermore, C. jepsonii forms a distinct lineage within the $C$. californica complex, as highlighted by the long branch leading to it (Fig. 1B), comparable in length to other species in this complex. 


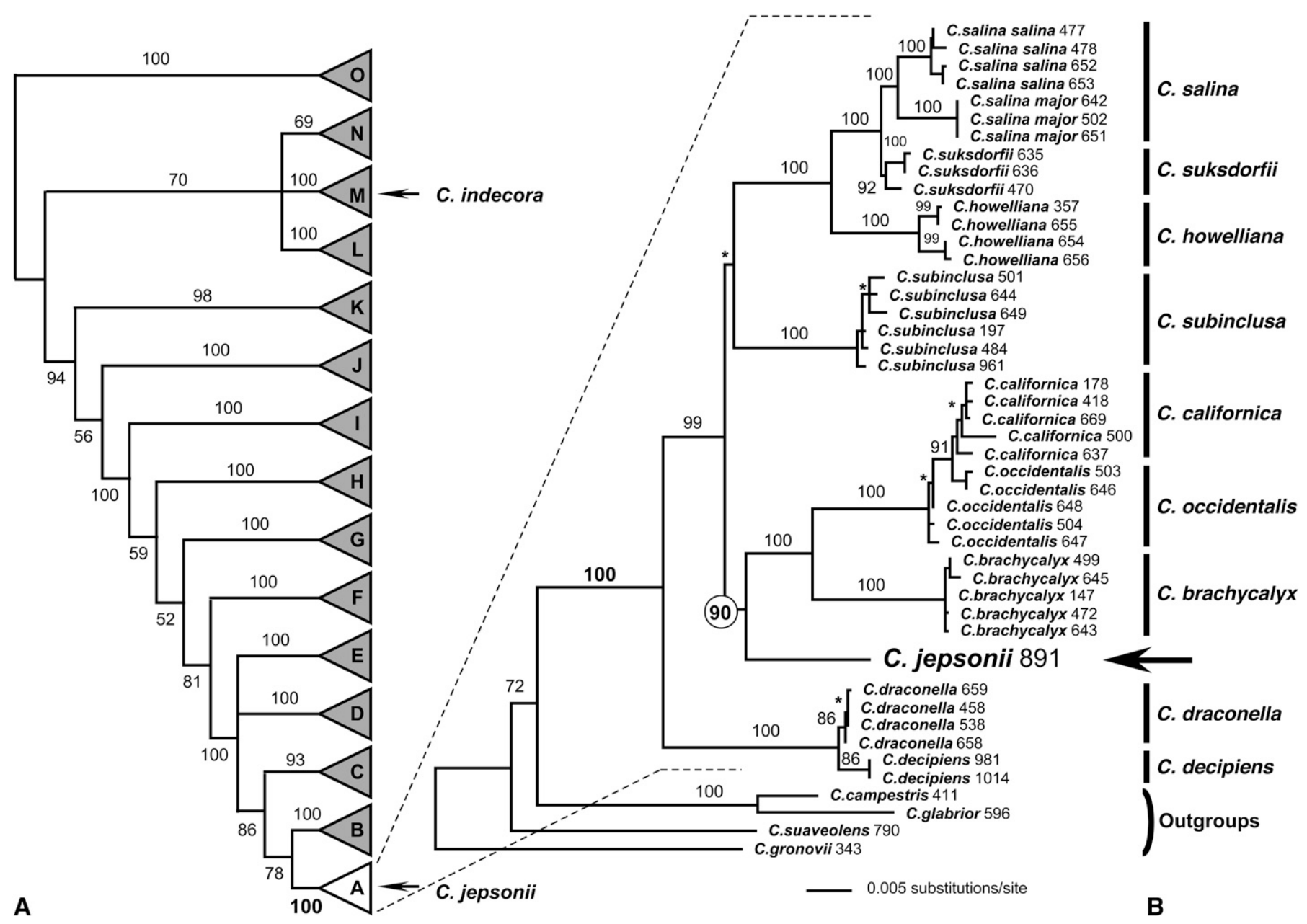

Fig. 1. Phylogenetic position of Cuscuta jepsonii. (A) Schematic overview of Cuscuta subg. Grammica phylogeny (strict consensus derived from the combined and $t r n L-F$ and ITS maximum parsimony analysis; see Stefanović et al., 2007 for details) depicting the relative positions of $C$. jepsonii and $C$. indecora. Fifteen major clades are labeled A-O; their bootstrap supports are indicated. (B) Majority-rule consensus tree with mean branch lengths from the Bayesian analysis of combined plastid (trn $L-F, r b c L$ ) and nuclear (ITS, 26S rDNA) data under the TIM + G model of DNA evolution showing fine-scale phylogenetic relationships of $C$. jepsonii with other species of $C$. californica complex (clade A). Bootstrap values are indicated for nodes supported at $\geq 50 \%$. Asterisks indicate branches with Bayesian posterior probability $<0.95$; all other branches have posterior probability $\geq 0.95$. Numbers following species names correspond to DNA accessions (see Costea and Stefanović, 2009).

In addition to resolving its phylogenetic placement, our results are consistent with the species status of $C$. jepsonii, as opposed to alternative taxonomic solutions that treated this entity as synonymous with either $C$. californica var. papillosa (Beliz, 1986) or C. indecora var. indecora (Beliz, 1993). Morphologically, $C$. jepsonii differs from all the species of the C. californica complex (Costea et al., 2006b) in having corolla lobes ca. $1 / 3$ as long as the corolla tube (Fig. 2; in the other species of the clade, corolla lobes are equaling or longer than corolla tube). The previous descriptions of morphology based on the holotype alone (Yuncker, 1921, 1932; Costea et al., 2006a) are accurate except for the infrastaminal scales, which although generally reduced to ridges, were found to be shortly bifid at the apex in one collection (Fig. 2D). Pollen is 3(-4)-zonocolpate, 17-22 $\mu \mathrm{m}$ long, subspherical to prolate (the latter more common), rounded at the poles; tectum is granulate, imperforate, or with only a few puncta, $0.2-0.3 \mu \mathrm{m}$ in diameter. Mature seeds, examined for the first time, are broadly elliptic to subround, $0.9-1.1 \times 0.8-1 \mathrm{~mm}$, dorsoventrally compressed, with a subterminal hilum.

\section{DISCUSSION}

Distribution, ecology, and conservation status of Cuscuta jepsonii-Based on the information from the newly found collections (Appendix 1), the geographical distribution of Jepson's dodder in California spanned from the High North Coast Ranges and Mount Shasta to the Southern Sierra Nevada. Unfortunately, all these collections are old: the two most recent specimens were collected in the 1950s; the others are at least 100 years old (see Appendix 1). An extensive search on the southern slopes of Mount Shasta (Siskiyou Co., CA; the second most recent known collection site) in July 2008 failed to discover this species, although the suitable California lilac hosts (Ceanothus, Rhamnaceae; discussed later) were present. Nevertheless, $C$. jepsonii may not be extinct. First, this is a small species, much less conspicuous than others in this genus, and if it is not extinct, it is most likely rare ("uncommon", Munz and Keck, 1959; also see Munz 16294 in Appendix 1). Second, most of the original collection sites are now part of extensive conservation 


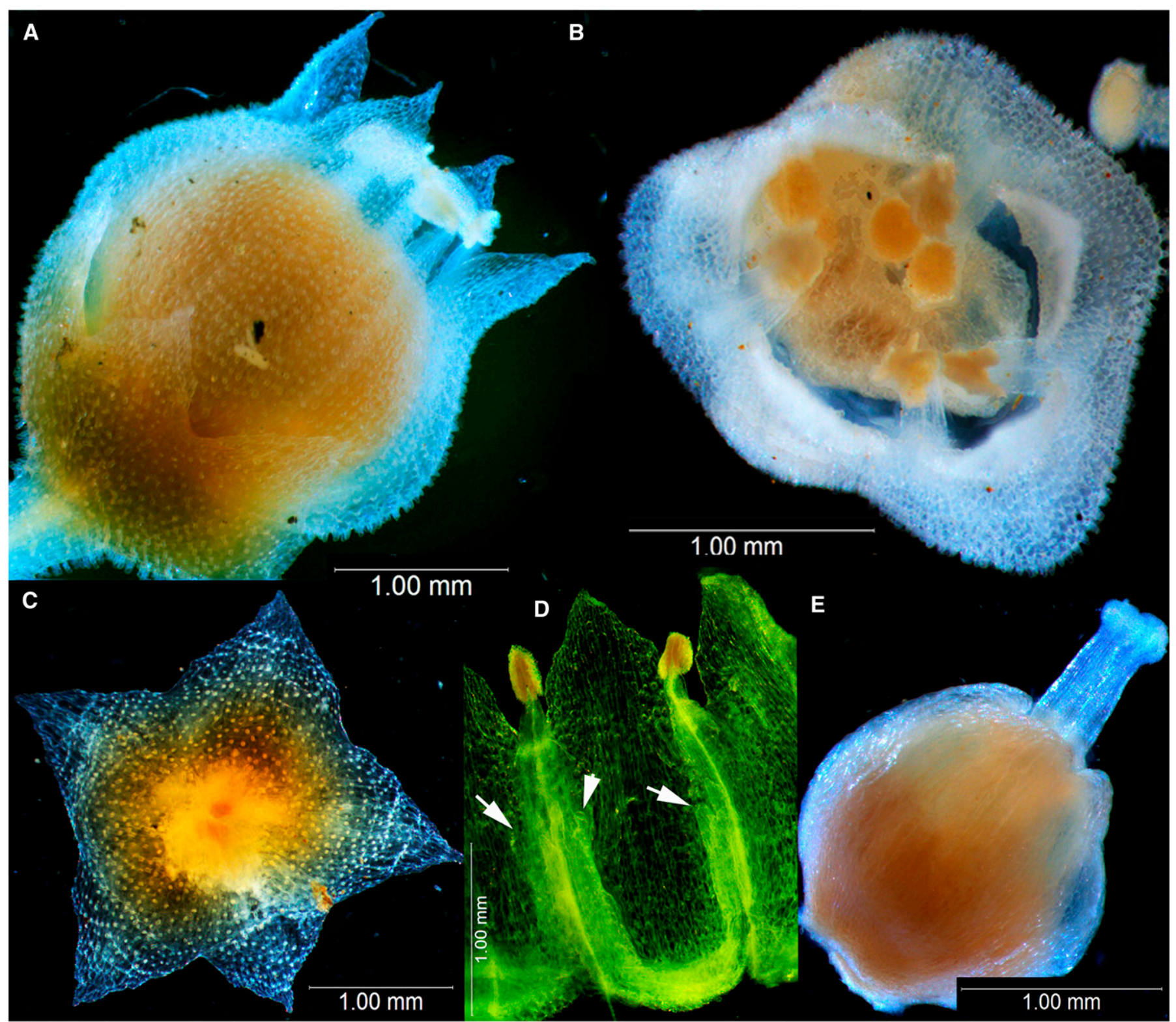

Fig. 2. Morphology of Cuscuta jepsonii. (A) Flower, lateral view. (B) Flower, view from above. (C) Calyx, dissected, dorsal view. Note that papillae on the calyx and corolla are arranged in rows similarly to C. indecora. (D) Corolla, dissected, showing stamens and reduced infrastaminal scales; arrows indicate short lateral fimbriae that make the scales bifid (fluorescent green is a digital manipulation created with Pax-it 6.8 to enhance contrast). (E) Gynoecium, lateral view. All images from Heller 5981 (CAS, RSA, UC) except (E), which is from Dudley 1774 (DS). Herbarium acronyms from Holmgren et al. (1990).

areas, e.g., Sanhedrin Mountain (proposed) and Yolla Bolly Middle Eel Wilderness Areas (parts of Mendocino National Forest), Shasta-Trinity National Forest, and Giant Sequoia National Forest. Finally, and perhaps most importantly, there have been no concerted efforts (besides our own) to locate this species. In brief, we suggest that $C$. jepsonii may be rediscovered, and we hope that the information presented here will provide the impetus to search for this species. Until then, the NatureServe (2009) conservation status category GH "Possibly Extinct-"Missing; known from only historical occurrences but still some hope of rediscovery"-is proposed for C. jepsonii.

The ecology of $C$. jepsonii was only mentioned briefly by Munz and Keck (1959) as "yellow pine forests," but more information can be inferred from its two known hosts: Ceanothus prostratus and $C$. diversifolius. The former species generally occurs in sunny, open sites on dry slopes and flats, in forests of Pinus jeffreyi, $P$. ponderosa, and Pseudotsuga menziesii at elevations ranging from 790 to $2700 \mathrm{~m}$ a.s.l. (Fross and Wilken, 2006; D. Burge, Duke University, unpublished data). Ceanothus diversifolius grows in more shaded places in relatively closed coniferous forests, often on cool but relatively dry ridges, flats, and drainages at elevations of 760-2300 $\mathrm{m}$ a.s.l. (Fross and Wilken, 2006; D. Burge, Duke University, unpublished data).

Host specificity: Conservation implications_-Host specificity and host preference vary greatly among parasitic plants (Parker and Riches, 1993; Heide-Jørgesen, 2008), and host-race formation is an important evolutionary driver (e.g., Norton and Carpenter, 
1998; Thorogood et al., 2008). Host specificity is also a crucial life history trait because it predefines the spatial limits within which a parasitic plant can occur and expand, both at the level of the ecosystem and at a geographical scale. The host-parasite interaction generates additional factors (e.g., host specificity and preference, host availability, host quality, host resistance to parasitism) that make the conservation of parasitic plants more challenging (Marvier and Smith, 1997).

Two empirical observations can be made about Cuscuta spp. from the point of view of their host specificity. First, the most successful dodders are the "generalists" that can parasitize plants from numerous families and genera. These Cuscuta spp. are usually weeds with a broad geographical distribution. Representatives of this category include: C. campestris, which is almost cosmopolitan in its distribution; $C$. indecora found across North and South America; C. americana from South America, West Indies, and parts of North America; $C$. gronovii in North America; as well as $C$. reflexa and $C$. japonica, mainly found throughout Asia, but locally introduced in other areas as well. The corollary of this observation is that dodders with conservation problems are "specialists," restricted to unique host genera or species. Among such species besides $C$. jepsonii are $C$. warneri on Phyla (Verbenaceae), C. polyanthemos on Chamaesyce (Euphorbiaceae), C. attenuata on Iva annua (Asteraceae), C. veatchii on Schinus discolor (Anacardiaceae) (for more examples, see Heide-Jørgesen, 2008). However, the host specificity for most of the Cuscuta spp. lies between these two extreme strategies because many dodders have adapted to parasitizing hosts that grow in a particular habitat from a certain geographical area.

The second observation is that specialized Cuscuta species are likely to become extinct before their hosts. For instance, $C$. warneri and $C$. jepsonii are both presumed to be extinct (Costea et al. 2006a). The former was known to parasitize Phyla cuneifolia and $P$. nodiflora, and the latter, Ceanothus prostratus and $C$. diversifolius, as indicated. These host species are all considered "secure-common; widespread and abundant" ("G5"), except for C. diversifolius, which has been assessed by NatureServe as having a conservation rank of "G3?" ("vulnerable?"). The same applies to all known hosts of Cuscuta species ranked G3 or rarer. In general, they have a substantially better conservation status than their Cuscuta parasites (NatureServe, 2009). The density of potential hosts represents a major limiting factor for Cuscuta populations that establish from seeds. Immediately after germination, the seedlings of Cuscuta have only 7-21 d to locate a host in their immediate proximity and establish a haustorial connection. If that does not occur, they will die (Dawson et al., 1994; Costea and Tardif, 2006). Therefore, any decline in the density or patchiness of the potential hosts will negatively impact the populations of Cuscuta. Cases in which the parasites are more likely to go extinct before their hosts have also been documented when the density of hosts modulates the success of infection (Lyles and Dobson, 1993).

Conclusions-The 1997 IUCN Red List of Threatened Species included 22 species of Cuscuta worldwide (Walter and Gillett, 1998), but this list has not been reevaluated against the more recent criteria (IUCN, 2007). Among the 37 species ranked by NatureServe (2009) from the USA and Canada, 14 are considered "at risk" (ranked G3 or rarer). According to these numbers, $\sim 38 \%$ of the Cuscuta species north of Mexico are in need of conservation. As is, this value is probably an underestimation for two principal reasons. First, some rare species (e.g., C. nevadensis) or even potentially extinct species (e.g., C. jepsonii) are not present on the list from the NatureServe. Second, given that $\sim 40$ Cuscuta species (from a total of $\sim 180$ worldwide) are known only from a single herbarium specimen (their respective types) and an additional $\sim 50$ are represented by no more than 2-5 collections, it becomes apparent that the biology and natural history of approximately one half of the species in the genus is essentially unknown. This uncertainty extends to their conservation status, likely to be G3 or rarer. Attempts to include Cuscuta species in more recent red lists or inventories are hindered precisely by this gap of information. For example, the red list of endemic plants from Peru (León and Roque, 2006) listed seven potential species of Cuscuta, but because similarly to $C$. jepsonii these species are known only from their types, they could not be assessed and assigned a conservation rank.

For these reasons, the traditional focus on pests and their control methods must be complemented with more systematics and biodiversity-oriented studies. The potential of some dodder species to cause agricultural damage cannot be ignored, but at the same time a shift from the "bad parasite" stereotype associated with these ecologically important plants is necessary. Only in this way can we diminish inequalities in knowledge and conservation and create the foundations upon which some of the contemporary policies can be challenged. Hence, our demand: Equal rights for parasitic plants!

\section{LITERATURE CITED}

Ameloot, E., K. Verheyen, J. P. Bakker, Y. De Vries, and M. Hermy. 2006. Long-term dynamics of the hemiparasite Rhinanthus angustifolius and its relationship with vegetation structure. Journal of Vegetation Science 17: 637-646.

Bardgett, R. D., R. S. Smith, R. S. Shiel, S. Peacock, J. Simkin, And H. QUIRK. 2006. Parasitic plants indirectly regulate below-ground properties in grassland ecosystems. Nature 439: 969-972.

Beliz, T. 1986. A revision of Cuscuta sect. Cleistogrammica using phenetic and cladistic analyses with a comparison of reproductive mechanisms and host preferences in species from California, Mexico, and Central America. Ph.D. dissertation, University of California, Berkeley, California, USA.

Beliz, T. 1993. Cuscuta. In J. Hickman [ed.], The Jepson manual of higher plants of California, 1st ed., 538-539. University of California Press, Berkeley, California, USA.

California Native Plant Society. 2009. Inventory of rare and endangered plants. Website http://www.cnps.org/ [accessed 7 April 2009].

Callaway, R. M., and S. C. Pennings. 1998. Impact of a parasitic plant on the zonation of two salt marsh perennials. Oecologia 114: 100-105.

Costea, M. 2007 onward. Digital atlas of Cuscuta (Convolvulaceae). Website https://www.wlu.ca/page.php?grp_id=2147\&p=8968 [accessed 13 April 2009].

Costea, M., G. L. Nesom, and S. Stefanović. 2006a. Taxonomy of the Cuscuta indecora (Convolvulaceae) complex in North America. Sida 22: 209-225.

Costea, M., G. L. Nesom, and S. Stefanović. 2006b. Taxonomy of the Cuscuta salina-californica complex (Convolvulaceae). Sida 22: 176-195.

Costea, M., and S. Stefanović. Molecular phylogeny of Cuscuta californica complex (Convolvulaceae) and a new species from New Mexico and Trans-Pecos. Systematic Botany 34 (3): 570-579.

Costea, M., and F. J. TARdif. 2006. Biology of Canadian weeds. Cuscuta campestris Yuncker, C. gronovii Willd. ex Schult., C. umbrosa Beyr. ex Hook., C. epithymum (L.) L. and C. epilinum Weihe. Canadian Journal of Plant Science 86: 293-316.

Dawson, J. H., L. J. Musselman, P. Wolswinkel, and I. Dörr. 1994. Biology and control of Cuscuta. Reviews of Weed Science 6: 265-317. 
DeBry, R. W., and R. G. Olmstead. 2000. A simulation study of reduced tree-search effort in bootstrap resampling analysis. Systematic Biology 49: 171-179.

Felsenstein, J. 1985. Confidence limits on phylogenies: An approach using the bootstrap. Evolution 39: 783-791.

Fross, D., And D. Wilken. 2006. Ceanothus. Timber Press, Portland, Oregon, USA.

Heide-JøRgesen, H. 2008. Parasitic flowering plants. Brill, Leiden, Netherlands.

Holm, L., J. Doll, E. Holm, J. Pancho, and J. Herberger. 1997. World weeds: Natural histories and distribution. John Wiley, Toronto, Ontario, Canada.

Holmgren, P. K., N. H. Holmgren, and L. C. Barnett. 1990. Index herbariorum, part I: The herbaria of the world, 8th ed. New York Botanical Garden, Bronx, New York, USA.

ITIS. 2009. Integrated taxonomic information system [online]. Website http://www.itis.gov [accessed 9 April 2009].

IUCN [INTERNATIONAL UNion FOR CONSERvation of Nature]. 2007. IUCN red list of threatened species [online]. Website http:// www.iucnredlist.org [accessed 24 August 2008].

Kuit, J. 1969. The biology of parasitic flowering plants. University of California Press, Berkeley, California, USA.

León, B., And J. Roque. 2006. Cuscutaceae endemic of Peru. Revista Peruana de Biología 13: 277-278.

Lyles, A. M., AND A. P. Dobson. 1993. Infectious diseases and intensive management: Population management, threatened hosts and their parasites. Journal of Zoo and Wildlife Medicine 24: 315-326.

Marvier, A. M., AND D. L. SMith. 1997. Conservation implications of host use for rare parasitic plants. Conservation Biology 11: 839-848.

MülLER, K. 2005. SeqState-Primer design and sequence statistics for phylogenetic DNA data sets. Applied Bioinformatics 4: 65-69.

Munz, P. A., AND D. D. KeCK. 1959. A California flora. University of California Press, Berkeley, California, USA.

NatureServe. 2009. NatureServe explorer: An online encyclopedia of life, version 7.0. Website http://www.natureserve.org/explorer [accessed 9 April 2009].

Nickrent, D. 2009. Parasitic plant connection. Website http://www.parasiticplants.siu.edu/ [accessed 15 April 2009].

Norton, D. A., AND M. A. CARPENTER. 1998. Mistletoes as parasites: Host specificity and speciation. Trends in Ecology \& Evolution 13: 101-105.

PARKer, C., AND C. R. Riches. 1993. Parasitic weeds of the world. Biology and control. CAB International, Wallingford, UK.

Pennings, S. C., AND R. M. Callaway. 1996. Impact of a native parasitic plant on salt marsh vegetation structure and dynamics. Ecology 77: 1410-1419.

Pennings, S. C., and R. M. Callaway. 2002. Parasitic plants: Parallels and contrasts with herbivores. Oecologia 131: 479-489.

Prather, A. L., R. J. Tyrl, And W. D. Warde. 1995. A taxonomic investigation of Cuscuta attenuata (Cuscutaceae) and related taxa. Sida 16: $447-458$.
Press, M. C., ANd G. K. Phoenix. 2005. Impacts of parasitic plants on natural communities. New Phytologist 166: 737-751.

Rambaut, A. 2002. Se-Al sequence alignment editor, version 2.0a11. Institute of Evolutionary Biology, Edinburgh, UK. Website http:// tree.bio.ed.ac.uk/software/ [accessed 23 July 2008].

Rambaut, A., AND A. J. Drummond. 2004. Tracer, version 1.3. Institute of Evolutionary Biology, Edinburgh, UK. Website http://tree.bio. ed.ac.uk/software/ [accessed 25 August 2008].

Rannala, B., AND Z. YANG. 1996. Probability distribution of molecular evolutionary trees: A new method of phylogenetic inference. Journal of Molecular Evolution 43: 304-311.

Rice, P. M. 2009. INVADERS database system [online]. Website http:// invader.dbs.umt.edu [accessed 15 February 2009].

Ronquist, F., ANd J. P. Huelsenbeck. 2003. MrBayes 3: Bayesian phylogenetic inference under mixed models, version 3.1.2. Bioinformatics 19: $1572-1574$.

Simmons, M. P., And H. Ochoterena. 2000. Gaps as characters in sequence-based phylogenetic analyses. Systematic Biology 49: 369-381.

Stefanović, S., M. Kuzmina, and M. Costea. 2007. Delimitation of major lineages within Cuscuta subgenus Grammica (dodders; Convolvulaceae) using plastid and nuclear DNA sequences. American Journal of Botany 94: 568-589.

Swofford, D. L. 2002. PAUP*: Phylogenetic analysis using parsimony (*and other methods), version 4.0b10. Sinauer, Sunderland, Massachusetts, USA.

Thorogood, C. J., F. J. Rumsey, S. A. Harris, and S. J. Hiscock. 2008. Host-driven divergence in the parasitic plant Orobanche minor Sm. (Orobanchaceae). Molecular Ecology 17: 4289-4303.

USDA, APHIS [Animal and Plant Health Inspection Service]. 2006. Plant protection and quarantine. Federal noxious weed list [online]. Website www.aphis.usda.gov/plant_health/plant_pest_info/weeds [accessed 8 April 2009].

USDA, NRCS [Natural Resources Conservation Service]. 2009. The PLANTS database [online]. Website http://plants.usda.gov [accessed 8 April 2009].

Walter, K. S., And H. J. Gillett. 1998. IUCN red list of threatened plants (1997). Compiled by the World Conservation Monitoring Centre. IUCN-World Conservation Union, Gland, Switzerland and Cambridge, UK.

WINDSOR, D. 1995. Equal rights for parasites. Conservation Biology 9: $1-2$.

YANG, Z., AND B. RANNALA. 1997. Bayesian phylogenetic inference using DNA sequences: A Markov chain Monte Carlo method. Molecular Biology and Evolution 14: 717-724.

YUNCKER, T. G. 1921 [reprinted 1970]. Revision of the North American and West Indian species of Cuscuta. Illinois Biological Monographs 6: 91-231.

Yuncker, T. G. 1932. The genus Cuscuta. Memoirs of the Torrey Botanical Club 18: 113-331. 
APPENDIX 1. Voucher information for the type and newly found specimens of $C$. jepsonii (herbarium acronyms from Holmgren et al., 1990). All specimens were collected in California, and vouchers are listed by county of origin.

County—Collection locality, Host, Date, Voucher (Herbarium).

Lake Co.-Holotype: Big Horse Mountain, South Fork of Eel River, host Ceanothus diversifolius, 3 Aug 1892, Jepson 5c (JEPS, fragment NY); foothills south of Mt. Sanhedrin, midway between Potter Valley and Hullville, host Ceanothus diversifolius, 25 Jul 1902, Heller 5981 (RSA, CAS, UC); Elk Mountain, 1220-1525 m, host Ceanothus diversifolius, 21 Jul to 16 Aug 1905, Tracy 2349 (UC). Shasta Co.-South slope of Mount Shasta, in dry ashy, volcanic soil, ponderosa pine, Douglas firs, oaks, true firs, host Ceanothus prostratus, 6 Jul 1954, McLeod s.n. (OSU). Tulare Co.-Region of Sequoia National Forest, vicinity of Homer's Nose, 1525 m, host Ceanothus diversifolius, 11 Jul 1897, Dudley 1774 (CAS). Trinity Co.-North Yolla Bolly Mountains, $2.5 \mathrm{mi} \mathrm{NW}$ of Stuart Gap, $1402 \mathrm{~m}$, infrequent on Ceanothus prostratus in yellow pine forest, 17 Jul 1951, Munz 16294 (RSA). 